\title{
EFFECT OF CROSSLINKED CHITOSAN AS A CONSTRAINED VOLUME ON THE IN VITRO CALCIUM CARBONATE CRYSTALLIZATION ANDRÓNICO NEIRA-CARRILLO*1, JAIME RETUERT ${ }^{1,2}$
}

\author{
FRANCISCO MARTINEZ² AND JOSÉ LUIS ARIAS \\ ${ }^{1}$ Faculty of Veterinary and Animal Sciences, University of Chile and Center for Advanced Interdisciplinary \\ Research in Materials (CIMAT). Santa Rosa 11735, P.O. Box 2-15. La Pintana, Santiago, Chile. \\ ${ }^{2}$ Faculty of Physics and Mathematics Science. Av. Tupper 2069, Box 2777, University of Chile. Santiago, Chile. \\ ${ }^{*}$ Corresponding author: Dr. Andrónico Neira-Carrillo. \\ (Received: 3 December 2007 - Accepted: 23 January 2008)
}

\begin{abstract}
The present work deals with the effect of the constrained volume given by crosslinked chitosan $(\mathrm{CHI})$ as a sphere on the in vitro $\mathrm{CaCO}_{3}$ crystallization. Crosslinked CHI was obtained with formaldehyde (FA), glutaraldehyde (GA), epichlorhydrine (EPCH) and poly (propylene glycol) diglycidyl ether (PPDGE) as crosslinking agents. Determination of swelling percentage (\%) of the crosslinked CHI spheres was carried out in TRIS buffer at pH 9. Spheres of high molecular weight were prepared using drops of $\mathrm{CHI}$ solution on $\mathrm{NaOH}$. In vitro $\mathrm{CaCO}_{3}$ crystallization using gas-diffusion method was done. In addition, a synthetically sulphonated containing polymethylsiloxane (S-PMS) was used as modifying additive on the $\mathrm{CaCO}_{3}$ crystals growth in a confined space of CHI. The degree of the crosslinking altered the diffusion of $\mathrm{CO}_{2}$ gas through the $\mathrm{CHI}$ spheres during the $\mathrm{CaCO}_{3}$ crystallization resulting in different and specific crystals morphologies.
\end{abstract}

Keywords: chitosan, crosslinking agents, gas-diffusion method, crystallization and calcite crystals.

\section{INTRODUCTION}

Biomineralization is a widespread phenomenon in nature by which living organisms influence the crystallization of inorganic minerals and leads to the formation of precisely controlled inorganic-organic composites (mollusk and egg shells, crustacean carapaces, echinoderm exoskeleton and spines, corals, bones and teeth), in which the minute organic part exerts substantial control on the mineralization process ${ }^{1,2}$. Thus, the resulted inorganic material shows uniform size particles, novel crystal morphology, specific crystallographic orientation and remarkable properties ${ }^{3,4}$. The control of mineralization by biological molecules and how crystal polymorphism and structure can be controlled by organic molecules additives has been extensively studied ${ }^{5,6}$. Small amounts of acid-rich proteins and proteoglycans play a major role in forming the biomineralized composites by influencing mineral crystal nucleation and growth ${ }^{7,8,9,10}$. Calcium carbonate $\left(\mathrm{CaCO}_{3}\right)$ represents one of the major inorganic mineral and has been extensively investigated. $\mathrm{CaCO}_{3}$ crystals have three polymorphs: calcite (hexagonal), aragonite (orthorhombic) and vaterite (hexagonal). In nature it growth is typically heterogeneous crystallization and occurs in association with surfaces in a constrained volume space. It is known that organisms produce a geometrically well define microenvironment, controlling not only the addition of the organic molecules but also the localization and velocity of ions flux, $\mathrm{pH}$ and supersaturation.

Furthermore, the mineralization mechanism is altered by different chemical groups (e.g., amine, sulfate, and carboxylate) and functionalized networks ${ }^{11,12}$ The resulting morphology of the in vitro crystals is an expression of different growth rates in the various crystallographic directions, modulated by the adsorbed additives present in solution. Different approaches have been used to synthesize specific polymorphs of $\mathrm{CaCO}_{3}$ in various forms such as: films, spheres, sponge-like structures, ligand-receptor complexes, block copolymers and synthetic polypeptides ${ }^{13,14,15,16}$. In order to understand the biogenic crystallization of inorganic materials using synthetic systems we investigate the effect of the constrained volume using sphere of crosslinked chitosan (CHI) on the in vitro $\mathrm{CaCO}_{3}$ crystallization. CHI spheres were prepared using drops of CHI solution on $\mathrm{NaOH}$. CHI (poly- $\beta$ - $(1 \rightarrow 4)$-2-amino-2-deoxy-D-glucose) is obtained through partial deacetylation of chitin (poly- $\beta(1 \rightarrow 4)$-2-acetamido2-deoxy-D-glucose) which is the second most abundant polysaccharide in nature ${ }^{17-20}$.

The work includes in this paper is therefore focused on the preparation of the confined space of $\mathrm{CHI}$ spheres from commercial $\mathrm{CHI}$ of high and low molecular weight and we study their effect on $\mathrm{CaCO}_{3}$ in vitro crystallization. The following crosslinking agents: formaldehyde (FA), glutaraldehyde (GA), 2-(chloromethyl) oxirane or epichlorhydrine $(\mathrm{EPCH})$ and poly (propylene glycol) diglycidyl ether (PPDGE) were tested. In addition, poly (methyl ethyl benzene sulfonic acid) siloxane polymer (S-PMS) was used as modifying sulphonated additive on $\mathrm{CaCO}_{3}$ crystallization in the confined $\mathrm{CHI}$ spheres. The synthesis and characterization of S-PMS was prepared through hydrosilylation and sulphonic reactions and its influence as a template on the $\mathrm{CaCO}_{3}$ crystals will be soon reported ${ }^{21}$.

\section{EXPERIMENTAL}

\section{Materials}

Chitosan samples of high molecular weight $(\mathrm{Mw}=350 \mathrm{kDa},>83 \%$ deacetylation) from Aldrich and low molecular weight ( $\mathrm{Mw}=70 \mathrm{kDa},>75 \%$ deacetylation) from Fluka were washed with acetone and methanol and dried to constant weight. Calcium chloride dihydrate, ethanol and Tris(hydroxymethyl) aminomethane were obtained from ACS-Merck and ammonium hydrogen carbonate was from J.T. Baker. These reagents were of the high available grade. The distilled water was obtained from capsule filter $0.2 \mu \mathrm{m}$ flow (U.S. Filter). The degree of swelling (\%) for each CHI spheres was estimated between dry and swollen spheres using an analytical balance (Precision-Hispana, model AE 200).

2. Formation of crosslinked CHI sphere and swelling (\%) determination

The concentration of the crosslinking agents was $5 \times 10^{-2} \mathrm{M}$ in $\mathrm{NaOH} 0.067$ $\mathrm{M}$ solution at $40^{\circ} \mathrm{C}$ for $3 \mathrm{~h}$. The spheres of crosslinked $\mathrm{CHI}$ were obtained using drops of CHI solution in the range of $0.25-5.0 \%$ in acetic acid at $5 \%$ on $\mathrm{NaOH}$. Spheres of CHI are formed in situ when drops of CHI solution is fall down on concentrated $\mathrm{NaOH}$ solution (Fig.1). Moreover, crosslinked spheres of $\mathrm{CHI}$ were prepared in the presence of S-PMS at concentration of $1 \%(\mathrm{wt} / \mathrm{vol})$. The introduction of S-PMS inside the sphere of CHI was done using microinjection technique with a syringe. The swelling percentage (\%) for each crosslinked $\mathrm{CHI}$ sphere were determined as follow: a dried sphere of $\mathrm{CHI}$ (vacuum for $1 \mathrm{~h}$ at $60{ }^{\circ} \mathrm{C}$ ) was put in a graduated beaker and then a known volume of buffer TRIS solution at $\mathrm{pH} 9.0$ was added until covering completely the spheres and transferred in a thermostatized bath at $40^{\circ} \mathrm{C}$ for $3 \mathrm{~h}$. After this time, the spheres were carefully dried with a filter paper and weight again. The determination of the swelling percentage (\%) was carried out with all $\mathrm{CHI}$ spheres, that is, with and without crosslinked CHI. The swelling percentage (\%) was calculated using the following equation:

Swelling $(\%)=($ swelling sample - dried sample) $/$ dried sample Equation $1(\%)=($ ws sphere-Wd Sphere $) \times 100$ Equation1.

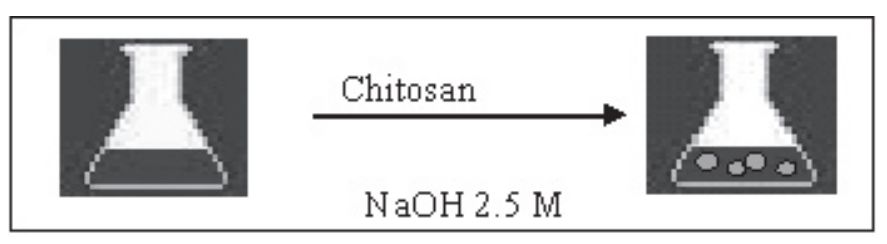

Figure 1. Experimental setup used for the preparation of the CHI spheres.

\section{In vitro $\mathrm{CaCO}_{3}$ Crystallization}

The gas-diffusion crystallizations (Fig.2) were done using a chamber consisting of $85 \mathrm{~mm}$ plastic Petri dish having a central hole in its bottom glued to a plastic cylindrical vessel. Inside the chamber, polystyrene microbridges with a crosslinked CHI sphere were filled with $35 \mu \mathrm{L}$ of $200 \mathrm{mM} \mathrm{CaCl}_{2}$ solution 
in $200 \mathrm{mM}$ TRIS buffer $\mathrm{pH} 9$. The cylindrical vessel contained $3 \mathrm{ml}$ of $25 \mathrm{mM}$ $\mathrm{NH}_{4} \mathrm{HCO}_{3}$ solution. All experiments were carried out inside the Petri dish using different $\mathrm{pH}$ at $20^{\circ} \mathrm{C}$ for $24 \mathrm{~h} . \mathrm{CaCO}_{3}$ crystals results from the diffusion of $\mathrm{CO}_{2}$ gas into the buffered $\mathrm{CaCl}_{2}$ solution. $\mathrm{CaCO}_{3}$ grown inside $\mathrm{CHI}$ spheres were collected and once rinsed with distilled water and on 50 to $100 \%$ gradient ethanol solution, dried at room temperature and then coated with gold using an EMS-550; automated sputter coater. $\mathrm{All} \mathrm{CaCO}_{3}$ crystals were observed in a Tesla BS 343 A microscope.

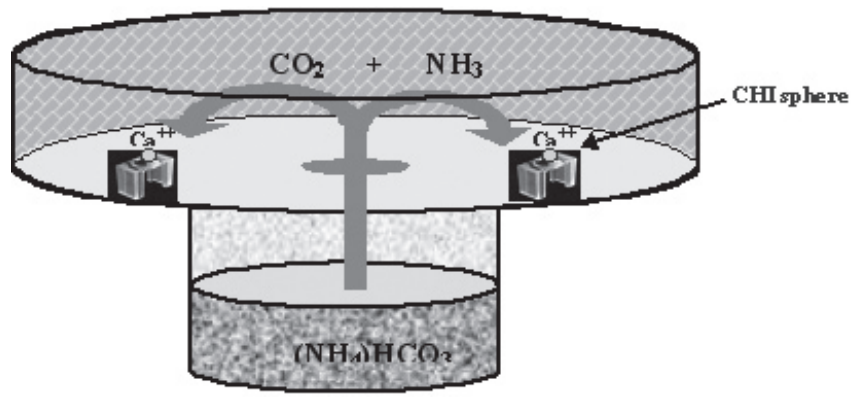

Figure 2. Experimental setup used for growing in vitro $\mathrm{CaCO}_{3}$ crystals.

\section{RESULTS AND DISCUSSION}

In order to find the optimal experimental condition for the formation of $\mathrm{CHI}$ spheres, different concentrations of $\mathrm{CHI}$ in acetic acid solutions at $5 \%$ in the range of $0.25-5.0 \%$ in $\mathrm{NaOH}$ were tested (Table 1).

Table 1. Experimental condition for the preparation of $\mathrm{CHI}$ spheres.

\begin{tabular}{|c|c|c|c|c|c|c|}
\hline $\begin{array}{c}\text { CHI } \\
\text { (HMW) }\end{array}$ & $0.25 \%$ & $0.50 \%$ & $0.75 \%$ & $1 \%$ & $2 \%$ & $5 \%$ \\
\hline $\begin{array}{l}\mathrm{NaOH} \\
2.5 \mathrm{M}\end{array}$ & $\begin{array}{c}- \\
\text { RD }\end{array}$ & $\begin{array}{c}+ \\
D<24 h\end{array}$ & $\begin{array}{c}+ \\
D<24 h\end{array}$ & $\stackrel{+}{+}$ & $\begin{array}{c}+ \\
D>24 h\end{array}$ & - \\
\hline $\begin{array}{l}\mathrm{NaOH} \\
5.0 \mathrm{M}\end{array}$ & - & $\begin{array}{c}+ \\
D<24 h\end{array}$ & $\begin{array}{c}+ \\
D<24 h\end{array}$ & $\stackrel{+}{D>24 h}$ & $\begin{array}{c}+ \\
D>24 h\end{array}$ & - \\
\hline $\begin{array}{c}\text { CHI } \\
\text { (LMW) }\end{array}$ & $0.25 \%$ & $0.50 \%$ & $0.75 \%$ & $1 \%$ & $2 \%$ & $5 \%$ \\
\hline $\begin{array}{l}\mathrm{NaOH} \\
2.5 \mathrm{M}\end{array}$ & - & - & - & - & - & $\stackrel{+}{\mathrm{D}>24 h}$ \\
\hline $\begin{array}{c}\mathrm{NaOH} \\
5.0 \mathrm{M}\end{array}$ & - & - & - & - & $\begin{array}{c}- \\
\text { RD }\end{array}$ & $\begin{array}{c}+ \\
D>24 h\end{array}$ \\
\hline
\end{tabular}

The - and + signals: correspond to the negative and positive formation of CHI spheres

RD: Radial disperstion of CHI sphere on the $\mathrm{NaOH}$ surface solution

$D<24 \mathrm{~h}$ : Spheres were formed but is deformed within $24 \mathrm{~h}$

$D>24 h$ : Spheres were formed and were stable $24 \mathrm{~h}$

We suspect that the crosslinking degree in the CHI spheres could alter the diffusion of $\mathrm{CO}_{2}$ gas through the sphere during the $\mathrm{CaCO}_{3}$ crystallization and will lead to the control of $\mathrm{CaCO}_{3}$ nucleation and changing the crystals morphology with some specific crystallographic orientation. The determination of the swelling percentage (\%) of the $\mathrm{CHI}$ and crosslinked $\mathrm{CHI}$ spheres for both molecular weight of CHI in TRIS buffer at $\mathrm{pH} 9$ is shown in the Fig. 3(a,b). The asterisk $(*)$ symbol in case of FA and GA indicates that they were used in acidic media, as well. Fig. 3(a) shows that GA and EPCH have a lower swelling percentage (\%) value than PPDGE and FA. Whereas PPDGE and FA showed higher swelling (\%) value that the control CHI sample. For both FA* and $\mathrm{GA}^{*}$, the acidic media was a better experimental condition for the crosslinking effectiveness in which the swelling (\%) decreased and more crosslinked spheres were obtained. Moreover, GA and EPCH produced good and defined unchanged CHI spheres after the swelling process. In case of (Fig.3b) all the crosslinking agents presented lower swelling (\%) value than the control sphere indicating that the effectiveness of these agents was better with LMW of CHI. Like in Fig.3a, EPCH and GA showed higher effectiveness of crosslinking degree.
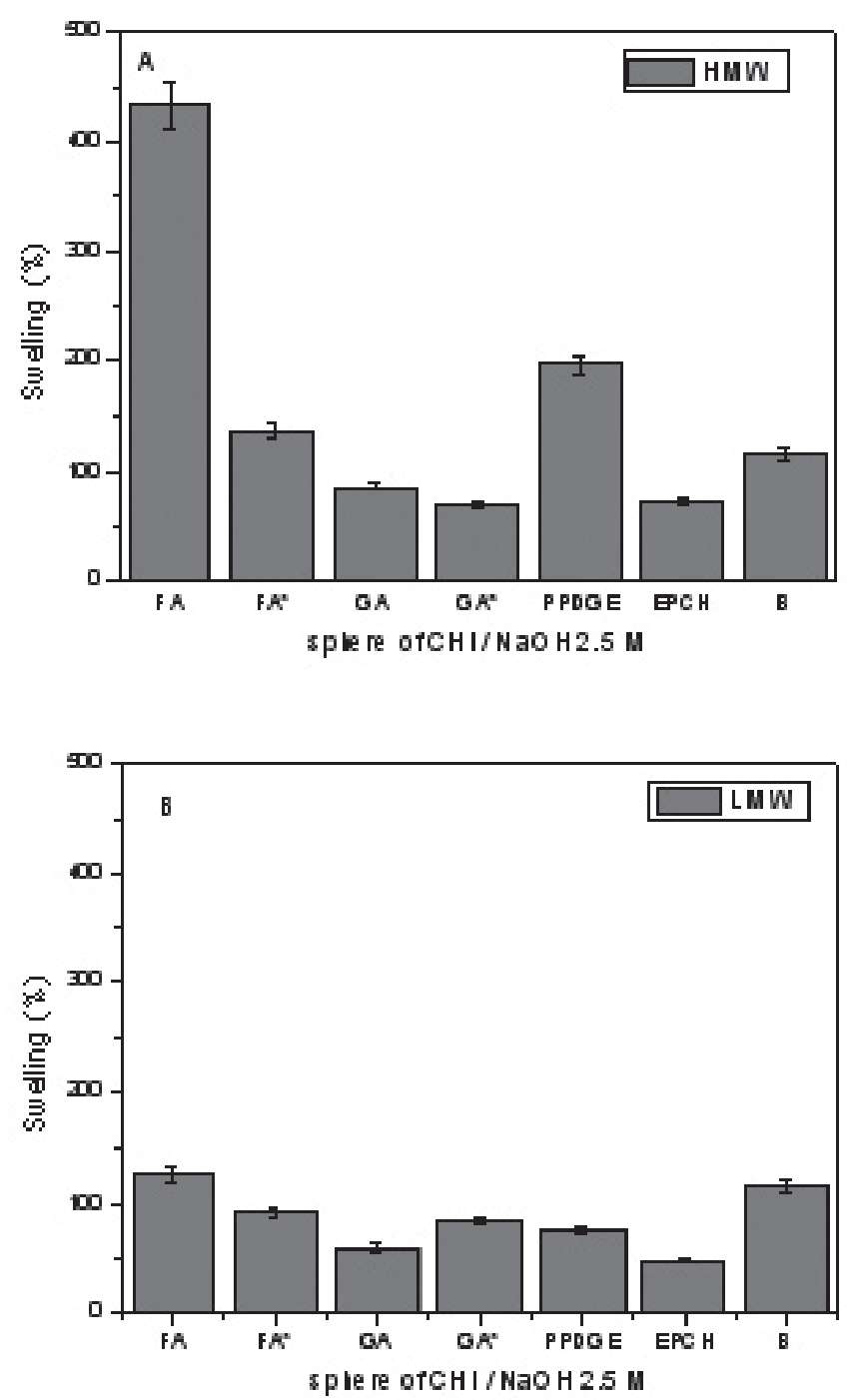

Figure 3. Swelling (\%) of CHI sphere (a) HMW and (b) LMW in buffer TRIS at pH 9. Column B in the graphs indicates uncrosslinked CHI Sphere as a blank. Where, Wd and Ws are weights of CHI Spheres in the dry and swollen states respectively.

Fig. $4(\mathrm{a}, \mathrm{b})$ shows a comparison of the swelling (\%) of crosslinked CHI sphere obtained in the presence of S-PMS for both molecular weights of CHI. As before, the asterisk $(*)$ for FA and GA indicates that they were used in acidic media and the symbol $+\mathrm{P}$ after the previous crosslinking agents in the graph indicates that the swelling process was done in the presence of S-PMS polymer. In the Fig.4a, the swelling value for FA, PPDGE and EPCH in the presence of S-PMS was lower than without this polymer. However, for GA in both media, the swelling (\%) was higher. This observation suggests that the presence of sulphonated moieties along the backbone of the chain of S-PMS polymer interacts with the amine group of $\mathrm{CHI}$ modifying the crosslinking process. However, when the S-PMS was introduced in CHI sphere of LMW (Fig.4b) the swelling (\%) value for FA (in both media) and EPCH do not change. For the crosslinked CHI sphere obtained with GA (in both media) and PPDGE the swelling (\%) value was higher. Thus, when the S-PMS polymer was microinjected into the $\mathrm{CHI}$ spheres modifyed the crosslinking process showing different swelling (\%). In general crosslinked CHI spheres for both high and low molecular weight prepared with GA and EPCH agents showed the lowest swelling (\%) value in the presence of S-PMS. 

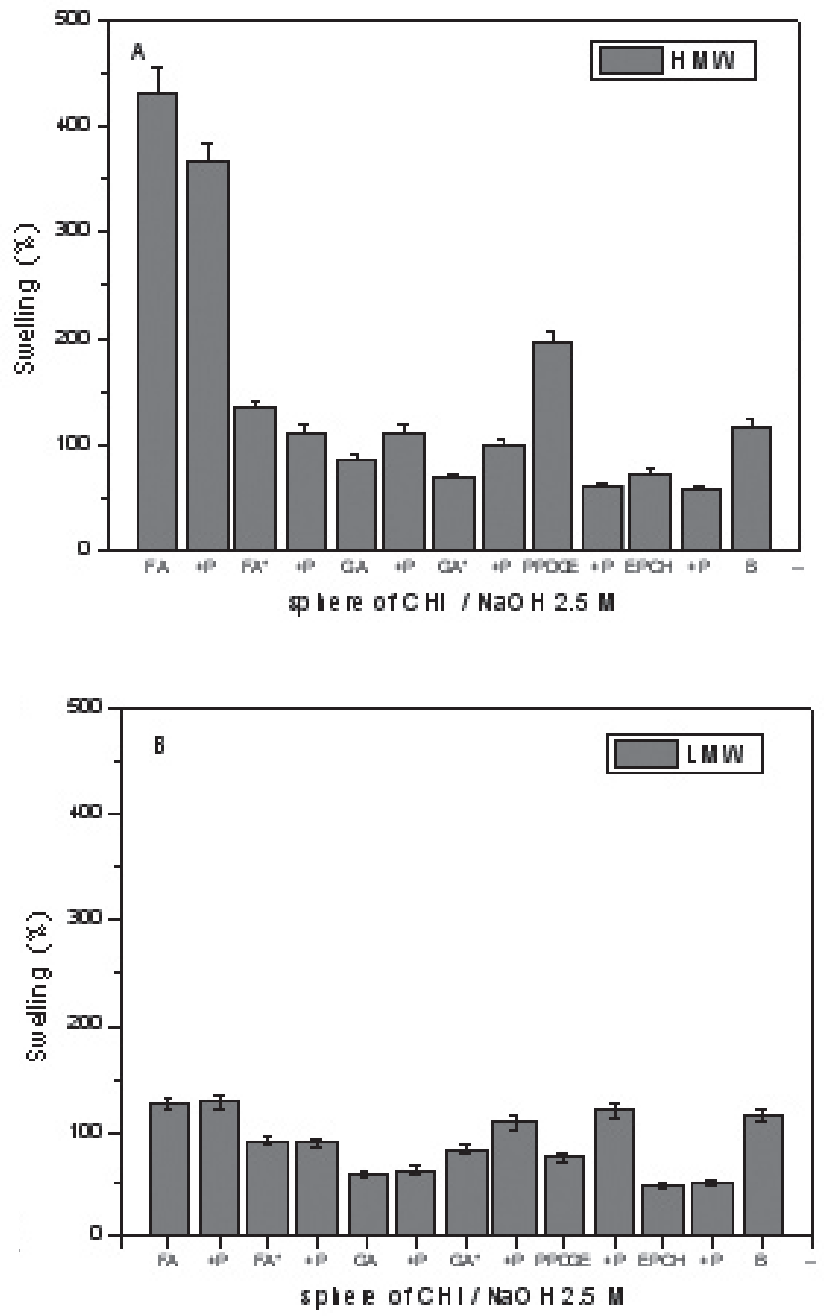

Figure 4. Swelling (\%) of CHI sphere (a) HMW and (b) LMW in the presence of S-PMS in buffer TRIS at pH 9. Column B in the graphs indicates uncrosslinked CHI Sphere as a blank.

In order to evaluated the effect of the crosslinked $\mathrm{CHI}$ as a constrained volume on the formation of $\mathrm{CaCO}_{3}$ crystals a set of in vitro crystallization experiments were performed with spheres of $\mathrm{CHI}$ using $\mathrm{HMW}$ of $\mathrm{CHI}$ prepared by soaking the spheres in the buffered $\mathrm{CaCl}_{2}$ solution (see Figure 2). The crystallization of $\mathrm{CaCO}$ was based on the gas-diffusion method in TRIS buffer $\mathrm{pH} 9$ at $20^{\circ} \mathrm{C}$ for $24 \mathrm{~h}$. The S-PMS was incorporated in situ during the formation of $\mathrm{CHI}$ spheres and used as an additive on the $\mathrm{CaCO}_{3}$ crystallization to observe its effect on the crystal morphology compared with crystals obtained without $\mathrm{S}$-PMS. If the presence of S-PMS affect the microenvironment obtained by the crosslinking agents in the crosslinked CHI spheres we will expect that the $\mathrm{CaCO}_{3}$ crystals show morphological modifications. In fact, SEM analysis showed that crystals growth in the crosslinked CHI sphere are dramatically influenced by the chemical microenvironment and was possible to reproduce experimentally similar crystals modifications obtained with biological molecules in nature.

By using the S-PMS at $1.6 \mathrm{mg} / \mathrm{ml}$, it was possible to obtained well defined $\mathrm{CaCO}_{3}$ crystals which were deposited on the surface of $\mathrm{CHI}$ sphere and growth inside of the sphere with different morphologies. Figure $5 \mathrm{~A}$ shows control $\mathrm{CaCO}_{3}$ crystals obtained without crosslinking agent, which resulted in rhombohedral calcite crystals in both outside (5As) and inside part (5Ai) of CHI spheres. These crystals are in a size range of 7 to $10 \mu \mathrm{m}$. When crystallization was carried out with crosslinked CHI spheres obtained with EPCH in the presence of S-PMS some corners of the crystals were rounded and the crystals faces were smooth and exhibited no etch pits (Fig. 5Bs). The size of these crystals was from 10 to $30 \mu \mathrm{m}$. However, all crystals grown inside the crosslinked sphere resulted in a mixture of small single crystals, which aggregates forming rosette-like crystals
(Fig. 5Bi). Moreover, these aggregated crystals are uniformly distributed in $\mathrm{CHI}$ sphere with size from 30 to $50 \mu \mathrm{m}$. The resulting aggregation of crystals grown inside indicated that it was possible to obtain in vitro calcite crystals with similar morphology to those occurring in some natural systems e.g.: in the eggshell membranes modulated by proteoglycans and proteins (see Fig. $7)^{10,22,23}$. Also, when the same crosslinking agent was used in the presence of S-PMS during the $\mathrm{CHI}$ sphere formation, we found similar aggregated $\mathrm{CaCO}_{3}$ crystals with major distribution (5Ci).
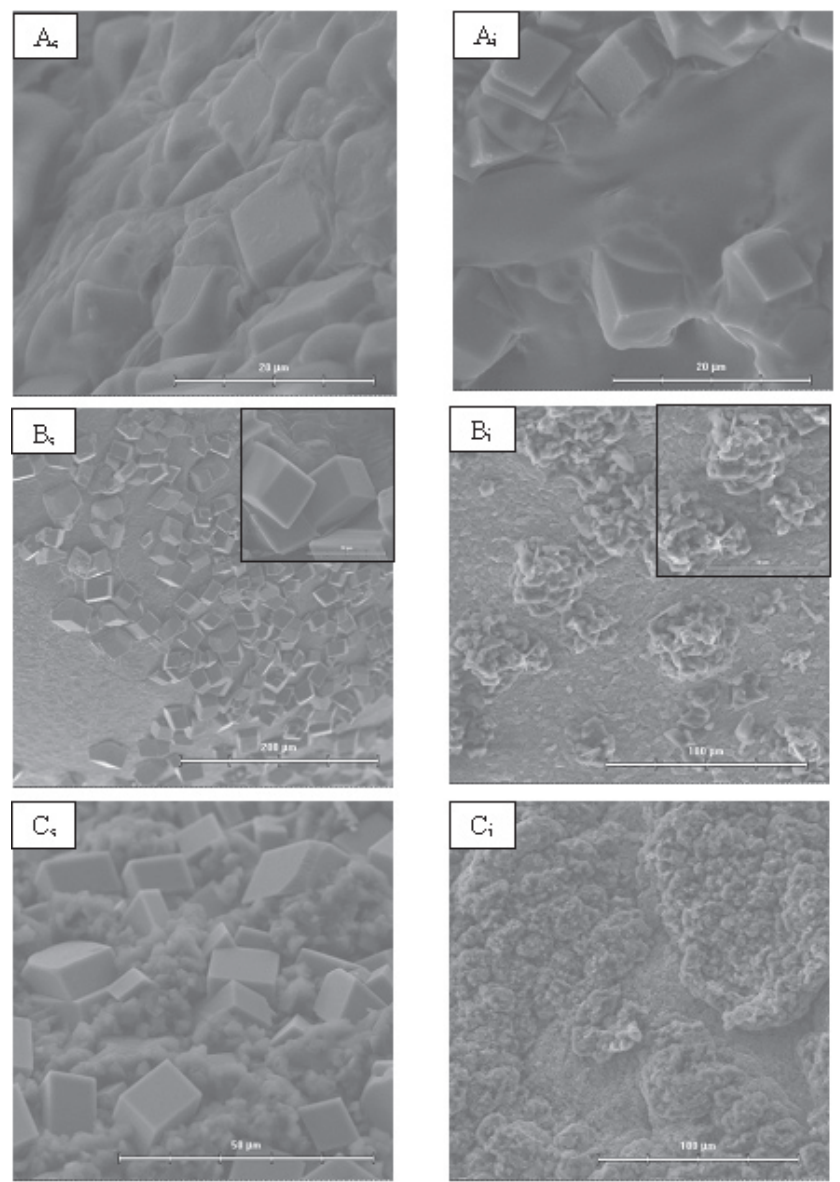

Figure 5. SEM of $\mathrm{CaCO}_{3}$ crystals grown in the presence of confined crosslinked HMW of CHI sphere with $\mathrm{EPCH}$ at $20^{\circ} \mathrm{C}$ for $24 \mathrm{~h}$. a) control calcite crystals b) EPCH + microinjected S-PMS and c) EPCH + in the presence of SPMS in solution. The sub-indexes S and I represent surface and internal part.

Figure $6(\mathrm{~A}-\mathrm{C})$ shows the $\mathrm{CaCO}$ crystals grown in the presence of crosslinked CHI sphere with GA at $20^{\circ} \mathrm{C}$ for $24 \mathrm{~h}$. Figure $6 \mathrm{As}$ shows $\mathrm{CaCO}_{3}$ crystals deposited on the $\mathrm{CHI}$ sphere surface which resulted in rhombohedra calcite crystals but with notorious corner modification. In contrast, fragmented $\mathrm{CaCO}_{3}$ crystals deposition was observed when crystals were grown inside the crosslinked CHI sphere (Fig. 6i). However, when the GA* agents with high effectiveness of crosslinking degree was used as template substrate, a very flat plate of $\mathrm{CaCO}_{3}$ crystals growth in the crosslinked $\mathrm{CHI}$ spheres demonstrating the strong influence of the chemical micro-environment. In addition, modified calcite crystals at the surface of crosslinked CHI spheres were observed (Figure $6 \mathrm{Bi}$ ). In the case of crosslinked sphere obtained with GA in the presence of S-PMS in solution, similar aggregated crystals composed with single small calcite crystals were observed (Fig. 6 Ci). The resulting crystals grown on the surface of the sphere show a typical rhombohedra calcite crystal characteristic of the control samples. The results obtained here are in accordance with the assumption that the presence of sulphonated S-PMS polymers leads to local accumulation of $\mathrm{Ca}^{2+}$ what relates with to the polymers nature, concentration, volume space and $\mathrm{pH}$ in the system. 

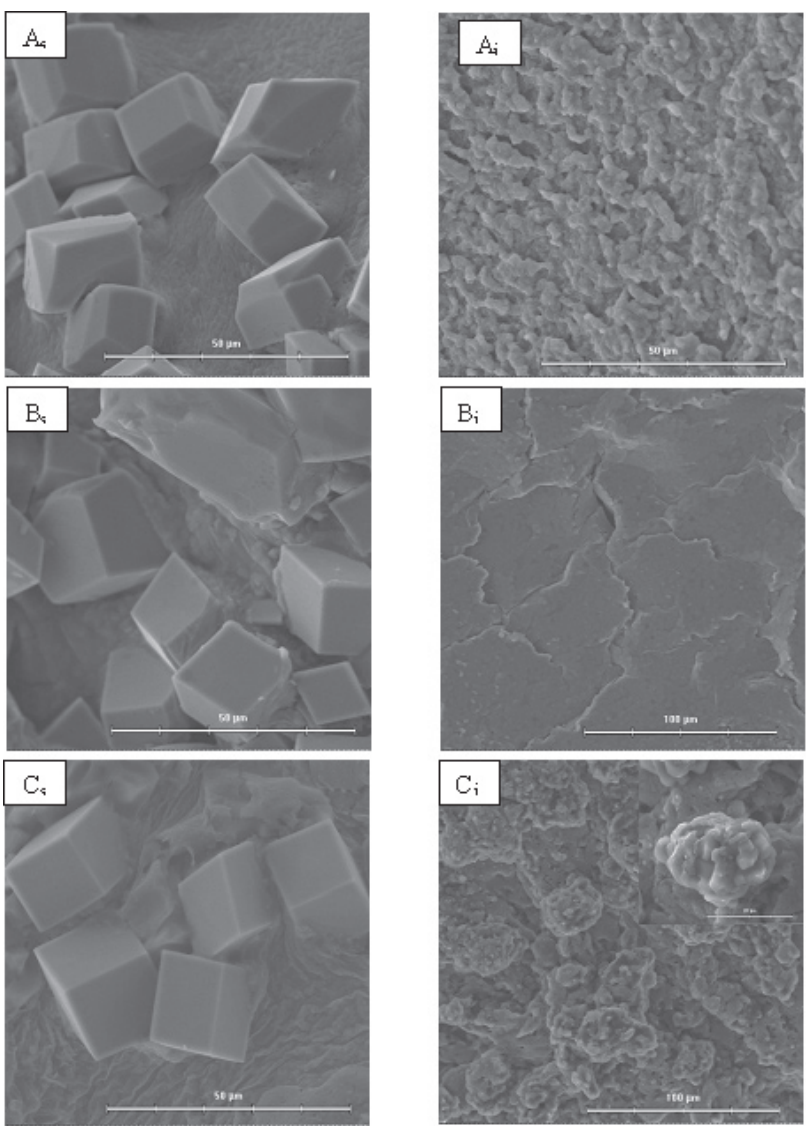

Figure 6. SEM of $\mathrm{CaCO}_{3}$ crystals grown in the presence of confined crosslinked HMW of $\mathrm{CHI}$ sphere with GA at $20^{\circ} \mathrm{C}$ for $24 \mathrm{~h}$. a) GA + microinjected S-PMS, b) GA* in acidic media + microinjected S-PMS and C) GA in the presence of S-PMS in solution. The sub-indexes S and I represent surface and internal part.

The role of proteins in biomineralization and the mechanism of eggshell formation are not well understood. Different isolated and purified proteins from chicken (ovocleidin 17, and C-type lectins) and gose eggshell matrix (ansocalcin) with homologous amino acid sequence have been obtained ${ }^{23}$. The polycrystalline aggregates growing on mammillae of the eggshell membrane ${ }^{22}$ with these biological proteins appear to be similar to calcite crystals randomly deposited inside the crosslinked $\mathrm{CHI}$ sphere. Figure 7 illustrate the capability to reproduce in vitro calcite crystals deposition on a synthetic substrate as compared with the natural post- oviposition eggshell membrane incubated in calcium chloride, at $\mathrm{pH} 7.4$ without any additive ${ }^{22}$. Understandings the role of various functional groups at the surface of synthetic polymers and how proteins control the morphological changes of the crystal in the natural bioceramics will increase our capability to understand the nucleation, growth and orientation processes and to develop functional and advanced biomaterials ${ }^{9,24}$.
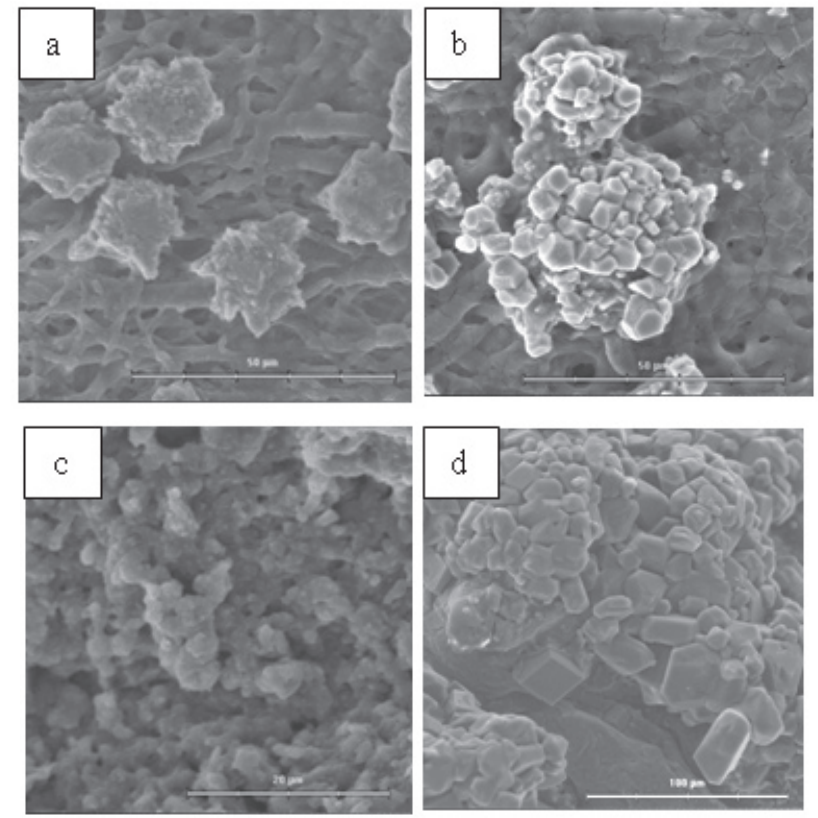

Figure 7. $\mathrm{SEM}$ of $\mathrm{CaCO}_{3}$ crystals showing a comparison of crystals grown in the presence of confined crosslinked HMW of CHI sphere at $20^{\circ} \mathrm{C}$ for $24 \mathrm{~h}$ (a) randomly deposited mammillae on external fibers of the shell membranes showing the Mamillary knob, b) $72 \mathrm{~h}$ incubation showing a bigger calcite growing on each mammillae (The pictures $7(a, b)$ were a courtesy of the author M.S. Fernández), c) crystals growth on the surface of CHI sphere in the presence of S-PMS without any crosslinking agent, d) crystals growth on the surface when GA + microinjected S-PMS is used.

The Figure 8 shows a summary of the calcite crystals grown inside the $\mathrm{CHI}$ spheres obtained after the in vitro $\mathrm{CaCO}$ crystallization at $20^{\circ} \mathrm{C}$ for $24 \mathrm{~h}$ Figure 8 (a-d) represents the crystals grown inside of crosslinked without SPMS. Figure 8 (e-1) shows the crystals morphology obtained in the presence of S-PMS using the microinjection technique (e-h) and in the presence of S-PMS in solution (i-1) crosslinked with EPCH, FA, GA and PPDGE, respectively. 

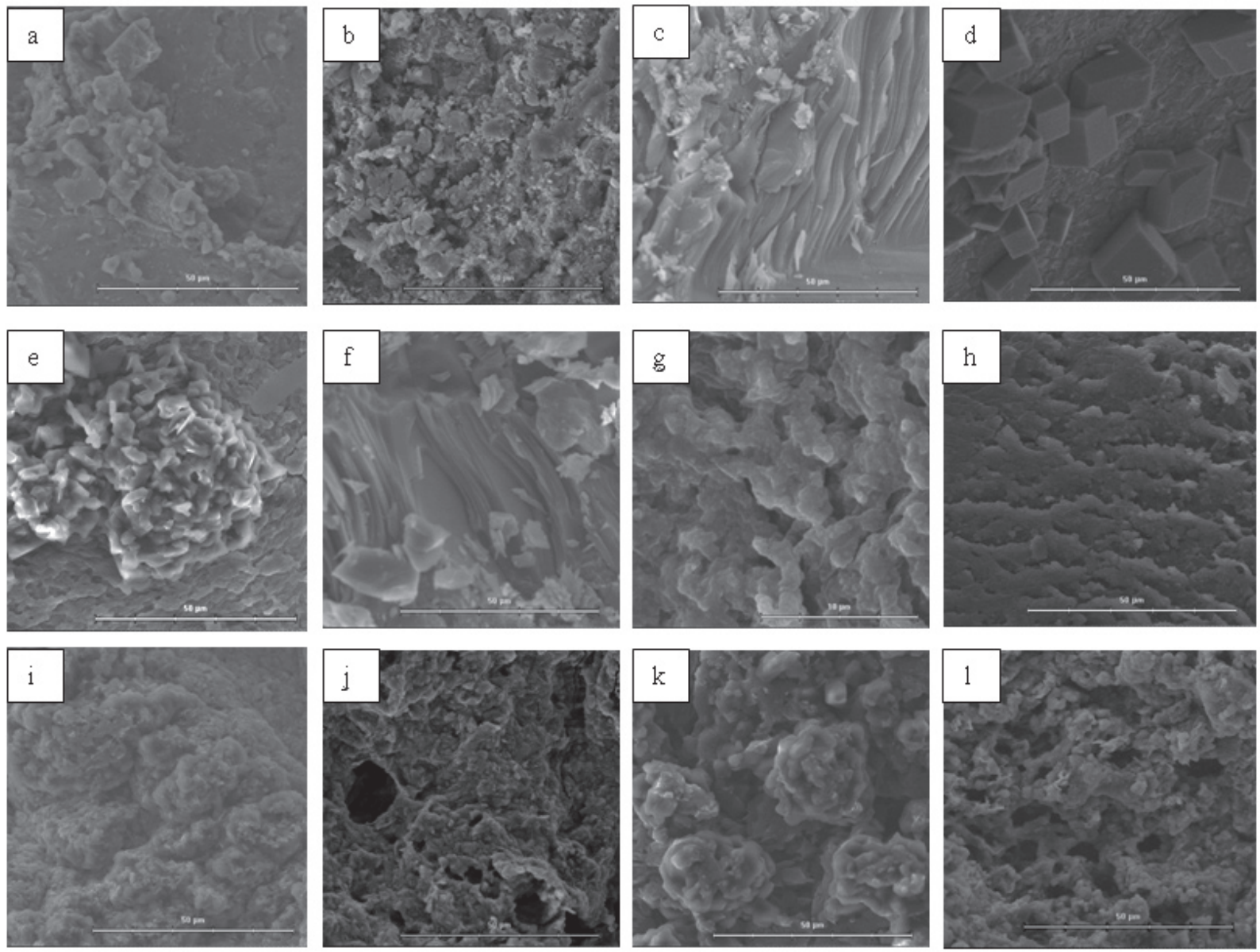

Figure 8. SEM of $\mathrm{CaCO}_{3}$ crystals grown inside the crosslinked CHI spheres (a-d) and crosslinked CHI sphere using S-PMS microinjected (e-h) and S-PMS in solution (i-1). a) EPCH, b) FA, c) GA, d) PPDGE, e) EPCH + microinjected S-PMS, f) FA + microinjected S-PMS, g) GA + microinjected S-PMS, h) PPDGE + microinjected S-PMS, i) EPCH + S-PMS in solution j) FA + S-PMS in solution k) GA + S-PMS in solution, 1) PPDGE + S-PMS in solution.

\section{CONCLUSIONS}

In summary, the crosslinking degree of the $\mathrm{CHI}$ sphere altered dramatically the flux of $\mathrm{CO}_{2}$ gas velocity during the in vitro $\mathrm{CaCO}_{3}$ crystallization showing inside of the CHI spheres different and specific crystals morphologies. The swelling test carried out with all crosslinking agents was close related with the crystals modification. The effect of GA and EPCH in contrast of PPDGE resulted more effective and weak, respectively. It was found that the presence of S-PMS can effectively control the morphogenesis of $\mathrm{CaCO}_{3}$ crystals which is strongly dependent of the chemical environment of the crosslinked $\mathrm{CHI}$ sphere. In addition, S-PMS can undergo changes in the charge of sulfonate groups and adopt different orientations in a confined space than in solution, and thereby elicit changes in $\mathrm{CaCO}_{3}$ morphology. We surmise that the crystallization of calcite, which is triggered by the sulphonated moieties of S-PMS, results from a local accumulation of $\mathrm{Ca}^{2+}$ ions which correlates closely with the polymer's nature, concentration, incubation time and $\mathrm{pH}^{26}$. Finally the use of functionalized polysiloxanes chemistry as an flexible additive in a confined space templates ${ }^{27,28}$ provides a viable approach for studying various aspects of biomineralization including production of controlled particles, polymorphism and defined morphologies.

\section{ACKNOWLEDGEMENT}

This research was supported by FONDAP 11980002 granted by the Chilean Council for Science and Technology (CONICYT) and Fund. Andes C-14060/31.

\section{REFERENCES}

1. H. A. Lowenstam, S. Weiner, On biomineralization, UK: Oxford Univ. Press, 1989.

2. S. Mann, Biomineralization: principles and concepts in bioinorganic materials chemistry. Oxford: Oxford Univ. Press, 2001.

3. S. Mann, J. Webb, R. J. P. Williams, Biomineralization, VCH, New York, 1989.

4. S. Mann, H. Cölfen, Angew. Chem. Int. Ed., 42, 2350, (2003)

5. F. C. Meldrum, Int. Mater. Rev., 48, 187, (2003)

6. H. Cölfen, Curr. Opin. Colloid Interf. Sci., 8, 23, (2003)

7. Y. Nys, M. T. Hincke, J. L. Arias, J. M. Garcia-Ruiz, S. E. Solomon. Poult. Avian Biol. Rev. 10, 142, (1999)

8. K. M. Simkiss, Wilbur. Biomineralization: cell biology and mineral deposition. San Diego (CA). Academic Press, 1989.

9. J. L. Arias, A. Neira-Carrillo, J. I. Arias, C. Escobar, M. Bodero, M., David, M. S. Fernández, J. Mater. Chem. 14, 2154, (2004)

10. J. L. Arias, M. S. Fernández, Mater. Charact. 50, 189, (2003)

11. I. Weissbuch, L. Addadi, M. Lahav, L. Leiserowitz, Science. 253, 637, (1991)

12. J. Aizenberg, J. Cryst. Growth, 211, 143, (2000)

13. T. Kato, Adv. Mater, 12, 1543, (2000)

14. R. K. Pai, S. Pillai, Cryst. Growth and Des. 7, 215, (2007)

15. A. Neira-Carrillo, M. Yazdani-Pedram, J. Retuert, M. Diaz-Dosque, S. Gallois, J. L. Arias, J. Colloid Interf. Sci, 286, 134, (2005)

16. H. Cölfen, S. Mann, J. Mater. Chem. 14, 2269, (2004)

17. K. Kurita, Prog. Polym. Sci. 26, 1921 (2001) 
18. M. N. V. Ravi Kumar, React. and Funct. Polym. 46, 1 (2000)

19. S. R. Payne, M. Heppenstall- Butler, M. F. Butler, Crys. Growth and Des. 7, 1262, (2007)

20. R. A. Muzzarelli, M. Mattioli-Belmonte, A. Pugnaloni, G. Biagini, EXS, 87, 251, (1999)

21. Works Under Progress. A. Neira-Carrillo, R.K. Pai, J. Retuert, M. S. Fernández, E. Carreño, J. L. Arias, 2008.

22. M. S. Fernandez, K. Passalacqua, J. I. Arias, J. L. Arias, J. Struc. Biol. 148, 1 (2004)
23. R. Lakshminarayanan, R. Manjunatha Kini, S. Valiyaveettil, PNAS 99(8), 5155, (2002)

24. J. L. Arias., D. A. Carrino, M. S. Fernández, J. P. Rodríguez, J. E. Dennis, A. I. Caplan, Arch. Biochem. Biophys. 298(1) 293, (1992)

25. J. M. Domínguez-Vera, J. Gautron, J. M. Garcia-Ruiz, Y. Nys, Poult. Sci. 79, 901, (2000)

26. O. Grassmann, P. Lobmann, Chem.-A Eur. J. 9, 1310, (2003)

27. H. Li, L. A. Estroff, J. Am. Chem. Soc. 129, 5480, (2007) 